\title{
Lyotropic Behavior of a Mono-tailed Glycolipid Assembly during Solidification and Melting of Electrolyte/Ice Eutectic Systems
}

\author{
Shigesaburo Ogawa, ${ }^{* \dagger}$ Kouichi Asakura, and Shuichi Osanai \\ Department of Applied Chemistry, Graduate School of Science and Technology, Keio University; 3-14-1 Hiyoshi, \\ Kohoku-ku, Yokohama 223-8522, Japan. \\ Received June 8, 2014; accepted October 9, 2014
}

The properties of low molecular weight glycolipids at subzero temperatures have been paid much attention due to their great potential for applications in cryopreservation. In this study, the ability of glycolipids to maintain their lyotropic properties was investigated by analyzing the aggregation behavior of octyl- $\beta$-Dglucoside $(\beta$-OGlu) during solidification and melting of electrolyte/ice eutectic mixtures using a simultaneous $X$-ray diffraction-differential scanning calorimetry measurement and cryomicroscopic observation. During the freezing process, eutectic formation increased the concentration of the $\beta$-OGlu micelle solution in the unfrozen phase, leading to ordering of the molecular assembly. The molecular assembly exhibited a reversible phase transformation between liquid crystalline phases (e.g., lamellar (L $\alpha)$ and hexagonal $(\mathrm{H})$ phases) and an isotropic micelle solution (I), depending on the degree of eutectic formation, which was regulated by temperature. Because the coexistence of electrolyte/ice eutectic often induces the dehydration of lipids, the persistence of lyotropic properties under such arid conditions demonstrates an attractive performance of glycolipids for use in low temperature applications, such as the cryopreservation of poorly water-soluble drugs or proteins.

Key words glycolipid; freezing; micelle; lyotropic liquid crystalline; eutectic

Non-ionic surfactants are frequently used to solubilize the poorly water-soluble materials. They can solubilize them inside micelle aggregates when the surfactant concentration exceeds the critical micelle concentration $(\mathrm{cmc})$. $^{1)}$ Among them, mono-tailed synthetic glycolipid (sugar-based surfactant), which is one of the industrially produced surfactant, is unique because it can be used to solubilize not only the poorly water-soluble drugs, ${ }^{2)}$ but also the water-insoluble membrane proteins. ${ }^{3-5)}$ It is well-known that membrane proteins are comprising an pivotal class of drug targets, and therefore, long term storages without functionality loss are greatly desired., ${ }^{4,5}$ In order to find an appropriate route for the accomplishment, the application of freezing-thawing (cryopreservation) or freeze-drying techniques using the micelle solution might be one of the satisfying methods. In that case, micelle aggregates would play a role as the stabilizing container that can greatly influence on the material stability under the preservation. However, to date, most of the study about the physico-chemical properties of mono-tailed synthetic glycolipids has been done above $0^{\circ} \mathrm{C}$, and the behaviors at subzero temperature have remained largely unknown. An understanding of the phase behaviors of the micelle aggregate under frozen situation must be indispensable as a primary knowledge toward the low temperature applications.

Octyl $\beta$-D-glucoside ( $\beta$-OGlu) is known as the representative mono-tailed glycolipid that is used as a membrane solubilizer $^{3-5)}$ (Chart 1). Also, it is known to form lyotropic liquid crystalline phases. ${ }^{6-8)}$ The materials that changes the aggregation structure in response to the hydration level of its hydrophilic components are defined as lyotropic liquid crystalline materials. ${ }^{9}$ Under ambient atmosphere, $\beta$-OGlu forms an isotropic micelle solution (I) and lyotropic liquid

The authors declare no conflict of interest

†Present address: School of Science and Technology, Kwansei Gakuin University; Sanda, Hyogo 669-1337, Japan. crystalline phases composed of hexagonal (H), cubic (Q), and lamellar $(\mathrm{L} \alpha)$ phases in a pure water system, depending on the hydration circumstance of its sugar moiety. ${ }^{6-8)}$ In our previous study, ${ }^{10}$ lyotropic phase transitions of liquid crystalline phases were observed due to the change of the concentration of $\beta$-OGlu during the ice freezing and thawing processes. Specific ice crystal growth from spherical to a hexagonal symmetry was recognized in the micelle solution. In addition, when an aqueous micelle solution of mono-tailed glycolipid was rapidly cooled to below $-42^{\circ} \mathrm{C}$, the glycolipid was concentrated by ice freezing and formed a glassy matrix of lyotropic liquid crystalline phases. It was also observed that the synthetic glycolipids kept the glassy phase consisted of the ternary system. ${ }^{11,12)}$

The $\mathrm{NaCl}$ dihydrate/ice eutectic is the physical mixture consisted of $\mathrm{NaCl}$ dihydrate and ice, and stable below $-21.3^{\circ} \mathrm{C}$. $^{13)}$ It was reported to induce significant dehydration of lipids, which led to irreversible phase changes. ${ }^{14)}$ With regard to the formation of eutectic, the synthetic glycolipids prevented the formation of the eutectic during the freezing-thawing process by forming a glassy phase when the molar ratio of $\mathrm{NaCl}$ in the matrix was low. ${ }^{11,12)}$ In this case, the glycolipids kinetically prevented the nucleation of eutectic in a simple aqueous $\mathrm{NaCl}$ solution. On the other hand, when the molar ratio of $\mathrm{NaCl}$ was substantially greater than the particular molar ratio of sugar moieties of glycolipid in the matrix, the formation of eutectic

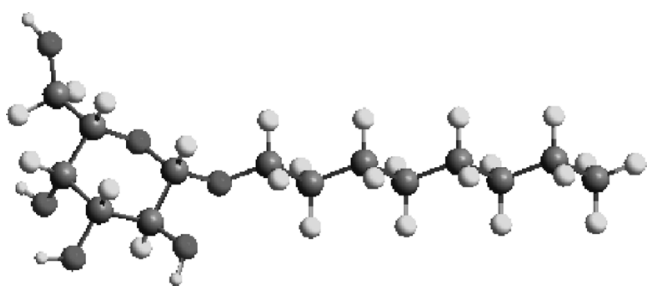

Chart 1. Structure of $n$-Octyl- $\beta$-D-glucoside ( $\beta$-OGlu) 
was not completely inhibited and a bulk eutectic formed, ${ }^{12)}$ which must be more practical case in the pharmaceutical formulations. In this case, the glycolipid molecules might withstand the dehydration under the competition between the persistence of hydration of sugar and the dehydration from the growth of eutectic. But the detail has not been analyzed and the glycolipid behaviors in such arid condition were obscure.

Later in this paper, we discuss the aggregation behavior of $\beta$-OGlu from micelle solution in the presence of an electrolyte/ ice eutectic. Because the water was the function to control the lyotropic liquid crystalline assemblies, the hydration property of mono-tailed glycolipid was qualitatively estimated. The ability of mono-tailed glycolipids to persist their lyotropic liquid crystalline property in the arid environment was demonstrated.

\section{Experimental}

Materials and Sample Preparation Water and the electrolytes were obtained from Wako Pure Chemical Industries, Ltd. (Osaka, Japan) and were used without further purification. $\beta$-OGlu was prepared by a procedure similar to that described in our previous report. ${ }^{10)}$ To prepare the sample solution, we dissolved the prescribed amounts of electrolyte and $\beta$-OGlu in water. The concentrations of the $\beta$-OGlu and electrolyte were expressed in the forms of weight percentage (wt $\%$ ) for the $\beta$-OGlu (e.g., $\beta$-OGlu in $\mathrm{g} /\left(\beta\right.$-OGlu $\left.+\mathrm{H}_{2} \mathrm{O}\right)$ in g) and weight molar percentage $\left(\mathrm{mol} \mathrm{kg}^{-1}\right)$ for the electrolytes (e.g., electrolyte in moles $/ \mathrm{H}_{2} \mathrm{O}$ in $\mathrm{kg}$ ).

Surface Tension Measurements The static surface tension $(\gamma)$ of aqueous $\beta$-OGlu solutions was determined for various compositions of $\beta$-OGlu and $\mathrm{NaCl}$ using an automatic digital Kyowa surface tensiometer, model CBVP-A3 (Kyowa Kaimen Kagaku Co., Ltd., Japan) with a Wilhelmy vertical plate. ${ }^{15)}$ Each $c m c$ was determined from the inflection point of a plot of the surface tension vs. concentration.

Simultaneous X-ray Diffraction-Differential Scanning Calorimetry (XRD-DSC) Measurements Simultaneous XRD-DSC were performed on a RINT-Ultima III unit (XRD-DSCII, Rigaku, Tokyo, Japan) connected to a Thermo Plus2 DSC (Rigaku). ${ }^{16)}$ These measurements were performed with non-hermetical square aluminum pans $(7 \mathrm{~mm} \times$ $7 \mathrm{~mm} \times 0.2 / 0.7 \mathrm{~mm}$ ). The measurements were performed over an angular range of $1^{\circ}-30^{\circ}(2 \theta)$ using $\mathrm{CuK \alpha}$ radiation $(1.54 \AA$, $40 \mathrm{kV}$, and $40 \mathrm{~mA})$ with a scan rate of $30^{\circ} \mathrm{min}^{-1}\left(2 \theta \mathrm{min}^{-1}\right)$. The lengths of the ordered structures were calculated by the Bragg equation: $\lambda=2 d \sin \theta$, where $\lambda$ is the wavelength of the $\mathrm{X}$-ray beam and $d$ is the length of the ordered structure.

DSC Measurements To analyze the thermal behaviors and phase-transition behaviors of the investigated systems, a model DSC 60 (Shimadzu Co., Ltd., Kyoto, Japan) connected to a cooling unit was used for calorimetric measurements. The instrument was calibrated on the basis of the melting temperatures of ice $\left(T_{\mathrm{m}}=0^{\circ} \mathrm{C}\right)$ and the $\mathrm{NaCl}$ dihydrate/ice eutectic $\left(T_{\mathrm{m}}=-21.3^{\circ} \mathrm{C}\right) .{ }^{13)}$ Each specimen was prepared by loading the sample into an aluminum pan, which was subsequently sealed hermetically.

Cryomicroscopy Ice and eutectic crystallizations and the phase changes of the unfrozen solution were observed by cryomicroscopy (BH, Olympus, Tokyo, Japan) with a CCD camera and a cryo-stage (Linkam, U.S.A.). The instrument was calibrated on the basis of the melting temperature of ice $\left(T_{\mathrm{m}}=0^{\circ} \mathrm{C}\right)$ and that of the $\mathrm{NaCl}$ dihydrate/ice eutectic
$\left(T_{\mathrm{m}}=-21.3^{\circ} \mathrm{C}\right) .{ }^{13)}$ A small volume of the solution was placed between a cover glass and slide glass. For the observation of the phases where a isotropic solution (micelle), liquid crystalline phases and ice coexisted, the polarization degree was reduced because of the isotropic nature of ice. ${ }^{10)}$

Low-Temperature XRD Measurements A separate Xray diffractometer equipped with a low-temperature stage and a $\mathrm{CuK \alpha}(\lambda=1.54 \AA)$ radiation source operated at $40 \mathrm{kV} \times$ $40 \mathrm{~mA}$ was used to collect low-temperature XRD patterns at a scan rate of $10^{\circ} \mathrm{min}^{-1}\left(2 \theta \mathrm{min}^{-1}\right)$ over the scanning range of $0^{\circ}$ to $40^{\circ}$.

\section{Results and Discussion}

Effect of High NaCl Concentration on the $\mathrm{cmc} \quad \beta$-OGlu forms micelle aggregates in aqueous systems above $\mathrm{cmc}$. In a pure water system, the $\mathrm{cmc}$ has been determined as $14.6 \mathrm{mM}^{15)}$ Therefore, at least $99.5 \%$ of molecules contribute to the formation of micelle aggregates at the concentration. When a large amount of $\mathrm{NaCl}$ was added to the system, the surface-tension curve shifted to lower concentrations (Fig. 1a), resulting in a decrease in the $c m c$. It indicates that the percentage of monomeric $\beta$-OGlu species that don't form micelle aggregates
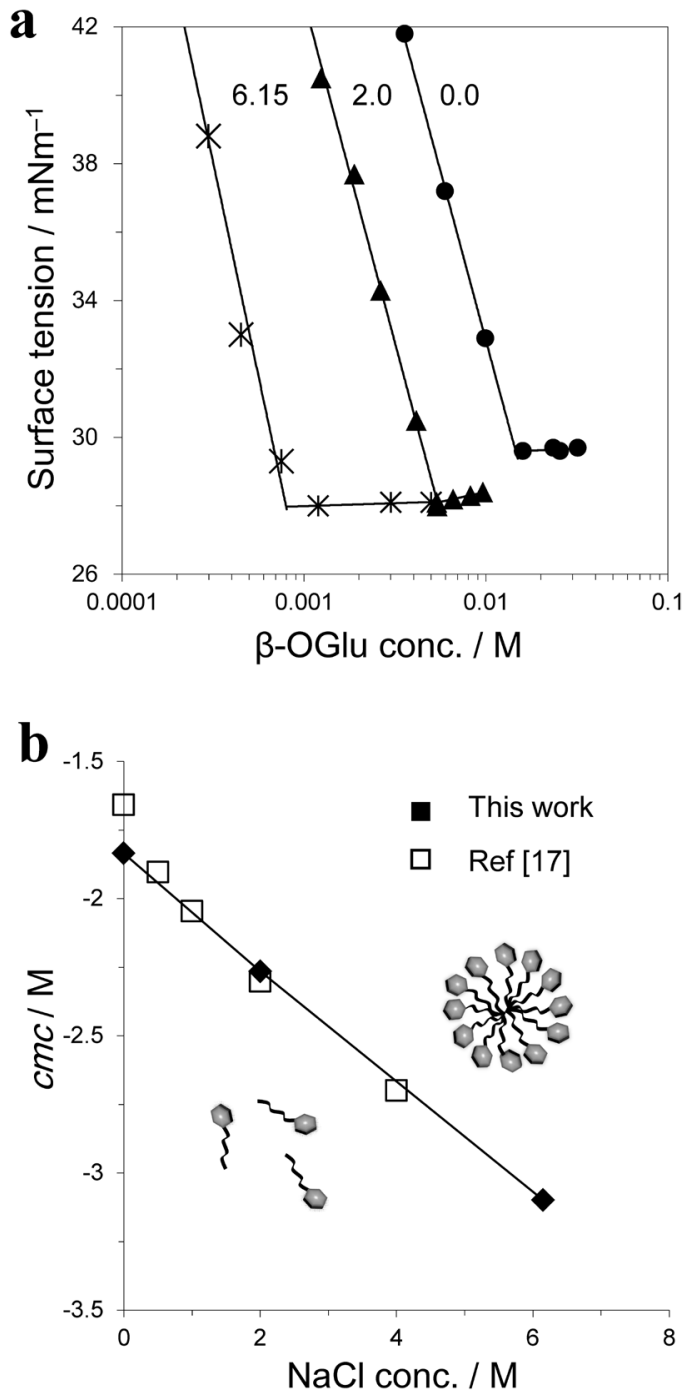

Fig. 1. (a) Variation in the Surface Tension as a Function of $\beta$-OGlu Concentration in Aqueous $\mathrm{NaCl}$ Solutions; (b) Effect of the $\mathrm{NaCl}$ Concentration on the $\mathrm{cmc}$ 
drastically increased with the $\mathrm{NaCl}$ concentration. Typically, the $c m c$ logarithmically decreased because of the salting-out effect, which was formulated by $\log c m c=-k C_{\mathrm{s}}+$ constant, where $k$ is a constant for the $\beta$-OGlu, $\mathrm{NaCl}$, and temperature and where $C_{\mathrm{s}}$ is the molar electrolyte concentration. ${ }^{17)}$ The sequential logarithmical decrease in the $c m c$ indicates that the $\beta$-OGlu molecules formed micelle solutions without phase separation at $\mathrm{NaCl}$ concentrations up to $6.15 \mathrm{M}$ (Fig. 1b).

Lyotropic Behavior in the Presence of the $\mathrm{NaCl}$ Dihydrate/Ice Eutectic Simultaneous XRD-DSC measurements were used to monitor the aggregation and thermal behaviors of $\beta$-OGlu during solidification and melting of $\mathrm{NaCl}$ dihydrate/ice eutectic (Fig. 2). With respect to the detection limit of the measurement, $10 \mathrm{wt} \%$ of $\beta$-OGlu was selected as the lowest concentration; $2.0 \mathrm{~mol} \mathrm{~kg}^{-1}$ was chosen as the $\mathrm{NaCl}$ concentration, which is lower than the eutectic composition $\left(5.2 \mathrm{~mol} \mathrm{~kg}^{-1}\right)^{13)}$ used to monitor both the ice crystallization and eutectic solidification processes as the model system where the molar ratio of $\mathrm{NaCl}$ was substantially greater than the molar ratio of sugar moieties of glycolipid that forms micelle aggregate. The temperature was controlled as shown in Fig. 2a, and the measurements under cooling were started in the presence of ice crystals. The remaining ice crystals were used as seed crystals to allow the system to freeze under nearly thermodynamic conditions, without a large degree of supercooling.

In the XRD-DSC charts in Fig. 2, the right figures show the DSC thermograms as functions of time, and left figures show the XRD patterns that correspond to each measurement time. Figure $2 b$ shows the measurement results collected under cooling. As shown in Fig. 2b, when the micelle solution was cooled in the presence of ice, the $\mathrm{NaCl}$ dihydrate/ice eutectic formed at temperatures less than $-25^{\circ} \mathrm{C}$ after the ice crystals grew further. The low-angle diffraction peak attributed to the $\beta$-OGlu assembly appeared at $c a .2 .95^{\circ}$ at $-30^{\circ} \mathrm{C}$, indicating that $\beta$-OGlu formed an ordered structure after eutectic solidified. The structural length was $c a .2 .89 \mathrm{~nm}\left(2 \theta=3.05^{\circ}\right)$ at $c a$. $-35^{\circ} \mathrm{C}$, and upon further cooling, shifted to $2.85 \mathrm{~nm}\left(2 \theta=3.1^{\circ}\right)$ at $c a .-45^{\circ} \mathrm{C}$. During the heating process, the low-angle diffraction peaks gradually shifted to lower angles during the melting of eutectic (Fig. 2c). The distance of the assembly shifted to $3.00 \mathrm{~nm}\left(2 \theta=2.94^{\circ}\right)$ from $2.85 \mathrm{~nm}\left(2 \theta=3.1^{\circ}\right)$ prior to the start of the main melting of eutectic.

The $d$ values became larger and finally vanished at the end of the melting of eutectic. Notably, the diffraction peaks between $2.98^{\circ}$ and $2.94^{\circ}$ changed at similar temperatures during both the freezing and thawing processes, as evident in Figs. $2 \mathrm{~b}$ and $\mathrm{c}$. These results demonstrate the lyotropic behavior of the $\beta$-OGlu assembly; this behavior is regulated by the concentration during both the solidification and melting of $\mathrm{NaCl}$ dihydrate/ice eutectic. Ragoonanan et al. have reported that an increase in the eutectic composition induces the detrimental dehydration of lipids. ${ }^{14)}$ Moreover, Zheng et al. have reported that heptaethylene glycol ether liquid crystalline systems readily solidify in the presence of eutectic composition. ${ }^{18)}$ Therefore, the cooperative changes in the aggregation state upon solidification and melting of eutectic demonstrate the attractive freeze tolerance of glycolipids with a sugar ring as their hydrophilic component.

Phase Behavior during Melting of Electrolyte/Ice Eutectic The phase behavior of $\beta$-OGlu assemblies during the melting of $\mathrm{NaCl}$ dihydrate/ice eutectic was studied. In our
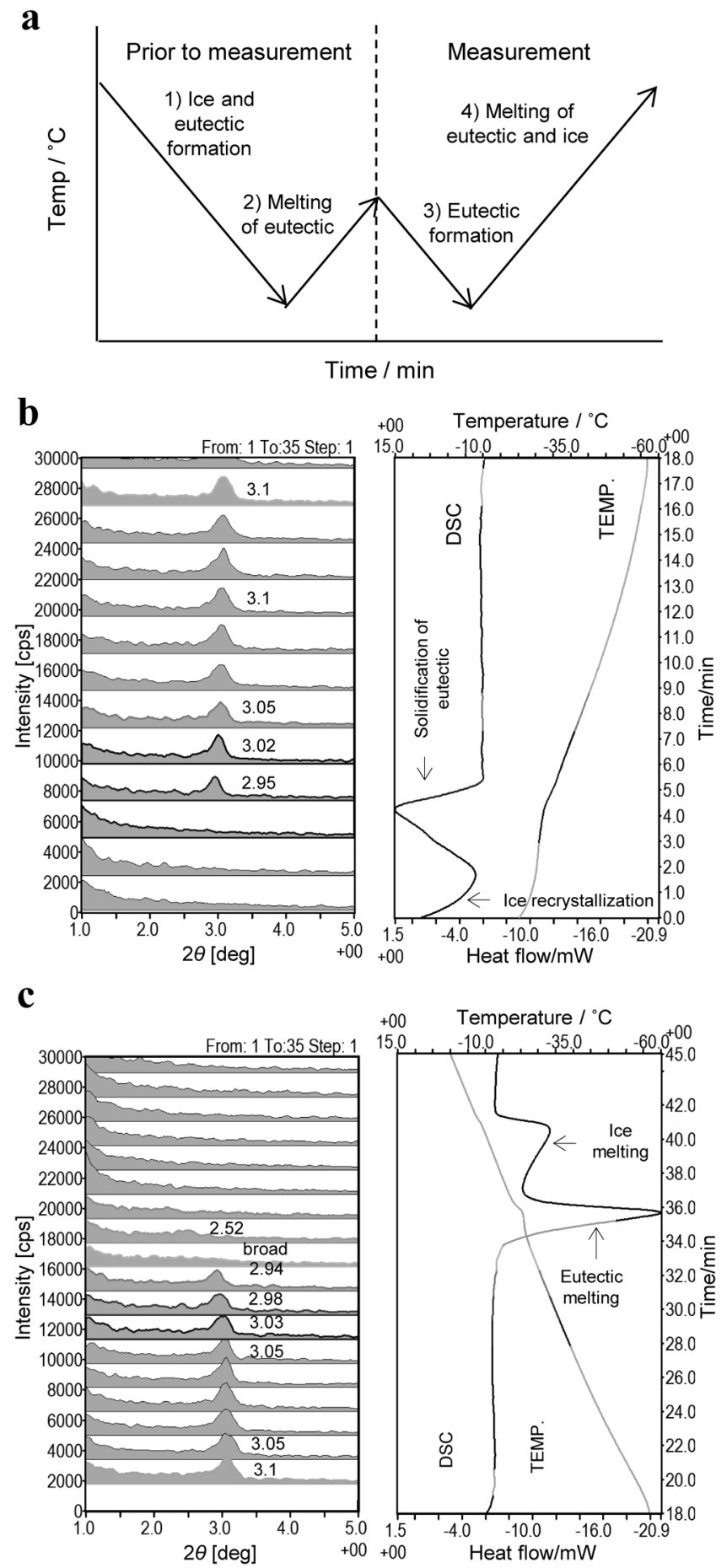

Fig. 2. XRD-DSC Chart of a Cooling $\left(3^{\circ} \mathrm{C} / \mathrm{min}\right)$ and Heating Cycle $\left(2{ }^{\circ} \mathrm{C} / \mathrm{min}\right)$ Performed on a $10 \mathrm{wt} \% \beta$-OGlu $2.0 \mathrm{~mol} / \mathrm{kg} \mathrm{NaCl}$ Solution

(a) Thermal protocol prior to and during the measurements. (b) Freezing process from -20 to $-60^{\circ} \mathrm{C}$ in the presence of a small amount of ice. (c) Thawing process from -60 to $0^{\circ} \mathrm{C}$.

preliminary study, we investigated the effect of $\mathrm{NaCl}$ on the phase-transformation temperature $\left(T_{\mathrm{tr}}\right)$ between the $\mathrm{H}$ phase and the I solution of $c a$. $63 \mathrm{wt} \% \beta$-OGlu/water mixture with various $\mathrm{NaCl}$ concentrations. Thermal analysis confirmed that the addition of $\mathrm{NaCl}$ decreased $T_{\mathrm{tr}}$ up to eutectic composition (Figure S1 in Supporting Information); i.e., the phase separation of glycolipids from the aqueous phase did not occur at lower temperatures. On the basis of this information, detailed 
analysis of the DSC thermograms and observations of phase textures during melting of eutectic were performed.

Figure 3 shows an enlarged DSC thermogram from the XRD-DSC results and the independently measured DSC thermograms using a different DSC apparatus. The $d$ values of the ordering structure obtained at each temperature by XRDDSC measurement are included in the figure. In Fig. 3a, the endothermic peaks depicted by three arrows were observed at $c a .-25.5,-23.5$, and $-22.5^{\circ} \mathrm{C}$ during the eutectic melting process. Note that those endothermic peaks were observed for DSC thermogram of same specimen (Fig. 3b, black above), but were not observed for DSC thermogram of aqueous $\mathrm{NaCl}$ solution in the absence of $\beta$-OGlu (Fig. 3b, gray), when the DSC measurements were independently performed. Those peaks became larger as increasing of $\beta$-OGlu concentrations (Fig. 3b, black below). In addition, the endothermic peaks were observed in the thawing DSC thermogram of $10 \mathrm{wt} \%$ of aq. $\beta$-OGlu solution around -7.0 and $-0.7^{\circ} \mathrm{C}$ (Figure S2, Supporting Information). They have been assigned to phase transition from $\mathrm{Q}$ phase to $\mathrm{H}$ phase and from $\mathrm{H}$ phase to $\mathrm{M}$ solution around -7.0 and $-0.7^{\circ} \mathrm{C}$ in our previous research. ${ }^{10)}$ Thus, it is reasonable to assign the endothermic peaks observed in thawing process of the ternary system as the phase transition between liquid crystalline phases. Because the aggregation sizes of the $\beta$-OGlu assembly $(3.50 \mathrm{~nm}$ or $2.85-3.00 \mathrm{~nm})$ were
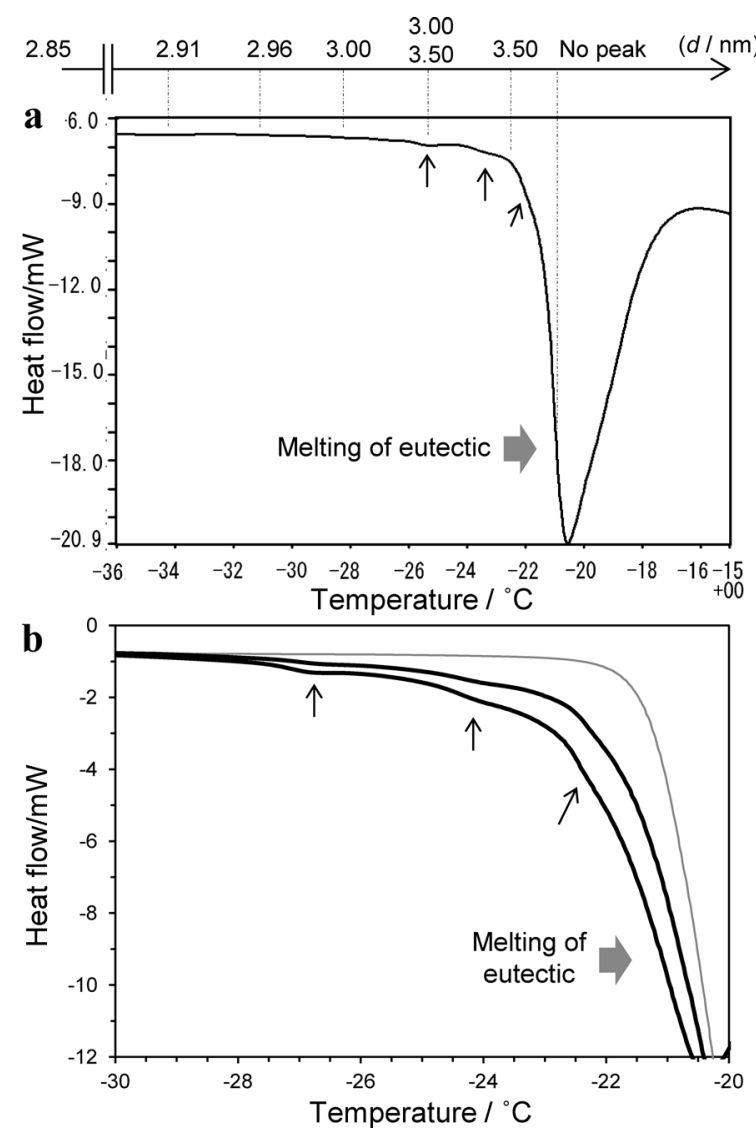

Fig. 3. (a) Enlarged DSC Thermogram of the Melting Process during a Simultaneous XRD-DSC Measurement; the Lengths of Structure Ordering Are Shown along the Top Axis

Arrows indicate the endothermic-like peaks. (b) DSC thermograms performed on a $10 \mathrm{wt} \% \quad \beta$-OGlu $2.0 \mathrm{~mol} / \mathrm{kg} \mathrm{NaCl}$ solution (black above), $20 \mathrm{wt} \% \quad \beta$-OGlu $2.0 \mathrm{~mol} / \mathrm{kg} \mathrm{NaCl}$ solution (black below) and $2.0 \mathrm{~mol} / \mathrm{kg} \mathrm{NaCl}$ solution (gray) at the heating rate of $3^{\circ} \mathrm{C} / \mathrm{min}$ using a different DSC apparatus. attributable to the $d$ values of the (100) plane of the H-phase and the (001) plane of L $\alpha$-phase, ${ }^{6}$ ) we assumed that each phase and coexisted phase must exist in the temperature range between $\mathrm{ca}$. -26 and $-23^{\circ} \mathrm{C}$ and in that below $-26^{\circ} \mathrm{C}$. The change in distance of molecular ordering $d$ shifted at temperatures less than $-30^{\circ} \mathrm{C}$, indicating the decrease of hydration level of L $\alpha$-phase. The variation of $d$ size of lamellar structure depending on the hydration level have been reported at room temperature. ${ }^{6}$ In Fig. 3b, the decrease of starting temperature of main melting of eutectic was observed in the presence of $\beta$-OGlu. The existence of freezing point depression of eutectic also indicates of the maintenance of hydration layers of $\beta$-OGlu molecules.

In the case of cryomicroscopic observations, a thermal treatment similar to that depicted in Fig. 2a was conducted prior to each observation. When the ice remaining in the specimen represented in Fig. 4(i) was cooled to $-40.0^{\circ} \mathrm{C}$, eutectic solidified, as observed in Fig. 4(ii) The eutectic was recognized as micron-sized black crystals. During the heating process, variation in the contrast was observed under a polarized condition (Figs. 4(iii), (iv), (v)). At ca. $-23.0^{\circ} \mathrm{C}$ (Fig. 4(iv)), the texture exhibited a high contrast, which was attributed to the appearance of birefringence. This birefringence disappeared when eutectic melting was completed at $c a .-21.3^{\circ} \mathrm{C}$ (Fig. 4(v)). This disappearance was assigned as the phase transformation from the birefringent $\mathrm{H}$ phase to the optically isotropic I solution. The large birefringence domain is the specific nature of $\mathrm{H}$ phase (Figure S3, Supporting Information). ${ }^{6,8,10}$ The correlation between the ordering size of the $\mathrm{H}$ phase and the lack of a peak for the I solution were supported by the XRD results. A higher contrast in Fig. 4(iii) compared with that in Fig. 4(v) supports the hypothesis that the birefringent $\mathrm{L} \alpha$ phase was formed. The formation of the $\mathrm{Q}$ phase, which was observed at the concentration between $\mathrm{H}$ phase and $\mathrm{L} \alpha$ phase at room temperature, was not observed. Karukstis et al. have reported that the Q phase solely existed in a very narrow composition region, and that most of the composition exist as the coexisting region with $\mathrm{H}$ or $\mathrm{L} \alpha$ phases. ${ }^{7}$ These observations explain why we did not observe the optically isotropic Q phase. On the basis of these results, we concluded that the $\beta$-OGlu assembly formed the lyotropic liquid crystalline phases during the solidification and melting of eutectic (Fig. 5).
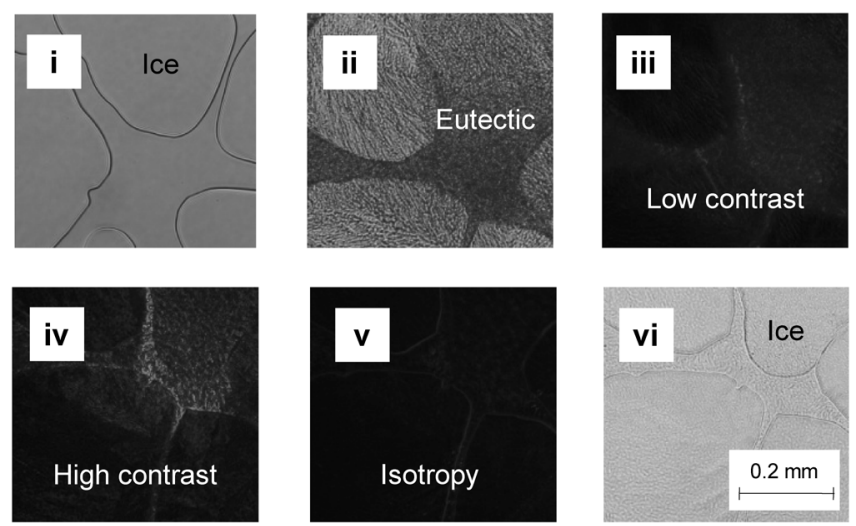

Fig. 4. Optical Microscopic Images at Various Temperatures during the Thawing Process of Eutectic in the $\beta$-OGlu/ $\mathrm{NaCl} /$ Water Ternary System

(i) $-30.0^{\circ} \mathrm{C}$, u.n.p.; (ii) $-40.0^{\circ} \mathrm{C}$, u.n.p.; (iii) $-30.0^{\circ} \mathrm{C}$, u.p.; (iv) $-23.0^{\circ} \mathrm{C}$, u.p.; (v) $-21.3^{\circ} \mathrm{C}$, u.p.; and (vi) $-21.1^{\circ} \mathrm{C}$, u.n.p. Note that u.n.p. and u.p. indicate "under non-polarized" and "under polarized" states, respectively. 


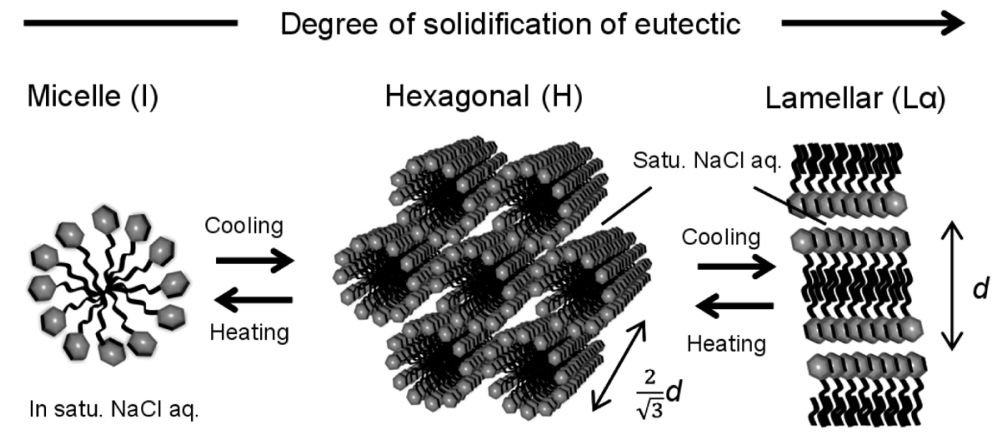

Fig. 5. Schematic Illustration of the Lyotropic Behavior of a $\beta$-OGlu Molecular Assembly during Solidification and Melting of Eutectic

a

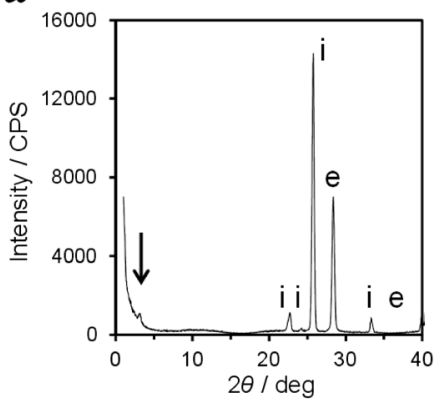

b

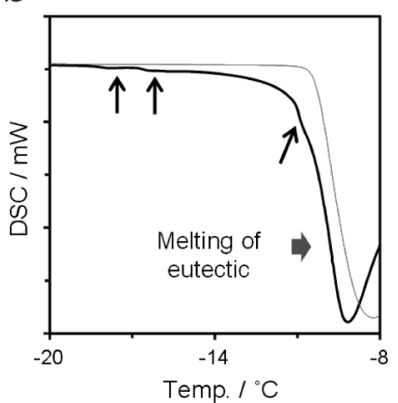

Fig. 6. (a) Low-Temperature XRD Charts for $10 \mathrm{wt} \% \beta$-OGlu $2.0 \mathrm{~mol} / \mathrm{kg}$ $\mathrm{KCl}$ Solutions at $-100^{\circ} \mathrm{C}$

i: Ice diffraction ${ }^{12)}$; e: diffraction of $\mathrm{KCl} /$ ice eutectic. $^{20)}$

(b) DSC Thermogram of the Thawing Process of the $\beta$-OGlu/KCl/Water Ternary System (Black Line) and $\mathrm{KCl} /$ Water Binary System (Gray Line)

Finally, the aggregation behavior of $\beta$-OGlu during the melting of $\mathrm{KCl} /$ ice eutectic was also investigated. $\mathrm{K}^{+}$is known to induce stronger dehydration than $\mathrm{Na}^{+}$according to the Hofmeister series. ${ }^{19)}$ Figure 6 a shows the XRD for a $\beta$-OGlu/ $\mathrm{KCl} /$ water system after the sample was cooled to $-100^{\circ} \mathrm{C}$. The appearance of the lower-angle diffraction peak indicates that an ordered structure with a size of $2.8 \mathrm{~nm}$ formed in the presence of the $\mathrm{KCl} /$ ice eutectic. In addition, the DSC thermogram of Fig. $6 \mathrm{~b}$ shows the three endothermic peaks in the $\beta$-OGlu/ $\mathrm{KCl}$ /water ternary system, while the aqueous $\mathrm{KCl}$ solution did not show them. These results also indicate the persistence of lyotropic behavior in the presence of a $\mathrm{KCl}$ and an ice eutectic system.

\section{Conclusion}

The aggregation behavior of $\beta$-OGlu was investigated in the presence of electrolyte/ice eutectic crystals. Owing to the attractive hydration property of the sugar moiety, the $\beta$-OGlu assembly exhibits lyotropic behavior from micelle solution, depending on its concentration, which was regulated by the temperature, even under competition with the solidification of eutectic, which often induce the significant dehydration of lipids. ${ }^{14,18)}$ Such attractive freeze tolerance properties that persist a lyotropic behavior without precipitating a crystalline are expected to contribute as the stabilizing containers to the preservation of water-insoluble drugs and membrane proteins under arid conditions.

Acknowledgments We thank Akira Kishi and Yayoi Taniguchi (Center for Applied Technologies, RIGAKU Corp., Japan) for help with the XRD-DSC simultaneous measurement and low-temperature XRD experiments. The other experiments were carried out at "OleoScience Laboratory" in Faculty of Science and Technology, Keio University, Yokohama, Japan.

\section{References}

1) Rangel-Yagui C. O., Pessoa A. Jr., Tavares L. C., J. Pharm. Pharm. Sci., 8, 147-165 (2005).

2) Hahn L., Sucker H., Pharm. Res., 6, 958-960 (1989).

3) Baron C., Thompson T. E., Biochim. Biophys. Acta, 382, 276-285 (1975).

4) Garavito R. M., Ferguson-Miller S., J. Biol. Chem., 276, $32403-$ 32406 (2001).

5) Koutsopoulos S., Kaiser L., Eriksson H. M., Zhang S., Chem. Soc. Rev., 41, 1721-1728 (2012).

6) Sakya P., Seddon J. M., Templer R. H., J. Phys. II, 4, 1311-1331 (1994).

7) Karukstis K. K., Duim W. C., Van Hecke G. R., Hara N., J. Phys. Chem. B, 116, 3816-3822 (2012).

8) Ogawa S., Asakura K., Osanai S., Carbohydr. Res., 345, 2534-2541 (2010).

9) Fong C., Le T., Drummond C. J., Chem. Soc. Rev., 41, 1297-1322 (2012).

10) Ogawa S., Asakura K., Osanai S., Phys. Chem. Chem. Phys., 14, 16312-16320 (2012)

11) Ogawa S., Osanai S., Cryobiology, 54, 173-180 (2007).

12) Ogawa S., Osanai S., "Supercooling," Chap. 3, ed. by Wilson P., InTech, 2012, pp. 29-54.

13) "Ullmann's Encyclopedia of Industrial Chemistry," 6th ed., Vol. 33, Chap. 2, Wiley-Vch, 1984, p. 208.

14) Ragoonanan V., Wiedmann T., Aksan A., J. Phys. Chem. B, 114, $16752-16758$ (2010).

15) Ogawa S., Asakura K., Osanai S., RSC Adv., 3, 21439-21446 (2013).

16) Arii T., Kishi A., Thermochim. Acta, 325, 151-156 (1999).

17) Lorber B., DeLucas L. J., Bishop J. B., J. Cryst. Growth, 110, 103-113 (1991).

18) Zheng L. Q., Minamikawa H., Harada K., Inoue T., Chernik G. G., Langmuir, 19, 10487-10494 (2003).

19) Dong R., Hao J., Chem. Rev., 110, 4978-5022 (2010).

20) Kajiwara K., Motegi A., Murase N., Cryo Letters, 22, 311-320 (2001). 